\title{
Epilepsy Revealing Fahr's Disease Associated with Hyperparathyroidism
}

\author{
Salem Bouomrani ${ }^{* 1,2}$, Mouna Guermazi ${ }^{1,2}$, Nesrine Regaïeg ${ }^{1,2}$ and Souad Yahyaoui $^{1}$ \\ ${ }^{1}$ Department of Internal medicine. Military Hospital of Gabes. Gabes, Tunisia \\ ${ }^{2}$ Sfax Faculty of Medicine. University of Sfax. Sfax, Tunisia \\ *Corresponding author: Salem Bouomrani, Department of Internal medicine, Military Hospital of Gabes, \\ Tunisia. E-mail: salembouomrani@yahoo.fr
}

Received Date: 18 January 2019; Accepted Date: 07 February 2019; Published Date: 14 February 2019

\begin{abstract}
Introduction: Fahr's disease (FD) is a rare anatomo-clinical entity, characterized by the presence of intracerebral calcifications of the basal ganglia, most often associated with phosphocalcic disorders, mainly hypoparathyroidism. Seizures are rare in this disease. We report the case of FD revealed by recurrent convulsive seizures taken medication for epilepsy for several years.
\end{abstract}

Case report: 26-year-old man followed since the age of 16 for recurrent generalized tonic-clonic seizures. Initial investigations were without abnormalities leading to the diagnosis of epilepsy. The patient was treated with sodium valproate with partial stabilization.

Since a year, the patient reported an increase in the frequency of epileptic seizures despite the strengthening of antiepileptic treatment. Cerebral CT scan showed the presence of multiple intracerebral calcifications with bilateral and symmetrical distribution, particularly in the central gray nuclei consistent with the diagnosis of FD.

Biological analysis showed hypercalcemia at $2.70 \mathrm{mmol} / \mathrm{l}$, hypophosphatemia at $0.4 \mathrm{mmol} / \mathrm{l}$, and the parathyroid hormone was increased to $172 \mathrm{ng} / \mathrm{l}$ confirming the diagnosis of associated primary hyperparathyroidism. Cervical ultrasound revealed an upper left parathyroid nodule.

After surgery of his adenoma, the subsequent evolution was marked by a net regression of the frequencies and the intensity of the seizures. Doses of valproic acid were significantly reduced.

Conclusion: Epilepsy remains a rare and unusual manifestation of FD. It can exceptionally be the inaugural symptom of the dis- ease. FD deserves to be known and screened for when the cause of seizure or epilepsy cannot be proven, especially since it is often associated with parathyroid disorders whose timely treatment can avoid secondary sometimes serious complications.

\section{Keywords}

Epilepsy; Fahr's disease; Hyperparathyroidism; Seizure

\section{Introduction}

Originally described by Karl Theodor Fahr in 1930 [1], Fahr's disease (FD) is a rare clinico-radiological neurodegenerative entity of unknown origin $[2,3,4]$. It is characterized by the presence of multiple bilateral and symmetrical intracerebral calcifications, particularly of the basal ganglia $[3,5,6]$. Its prevalence is estimated at less than 1/1,000,000 [7] and there are currently two forms of FD: sporadic or idiopathic FD $[3,6,8]$ which is the most common, and familial or hereditary FD also called "Primary Family Brain Calcification, PFBC" [2,9]. These familial forms are autosomal dominant $[2,8]$ and several mutations have been identified among which are mutations in SLC20A2, PDGFRB, and PDGFB $[2,8]$.

Calcifications of the basal ganglia that characterize FD cause neuropsychiatric manifestations, mainly extrapyramidal signs, and cognitive decline, which are common during this disease $[2,3,4,6]$.

Epilepsy, however, remains an exceptional manifestation during FD [10] and the inaugural forms are very little known, often described as "unusual", and are at the origin of an important diagnosis delay [8]. We report the case of FD revealed by recurrent seizures while taken medication for epilepsy for several years. 
Citation: Bouomrani S, Guermazi M, Regaieg N, Yahyaoui S (2019) Epilepsy Revealing Fahr's Disease Associated with Hyperparathyroidism. Curr Adv Neurol Neurol Disord 2019: 52-55. DOI: https://doi.org/10.29199/2637-6997/CANN-201023

\section{Case Report}

26-year-old man followed since the age of 16 for recurrent generalized tonic-clonic seizures. Initial investigations were without abnormalities leading to the diagnosis of epilepsy. The patient was treated with sodium valproate with partial stabilization.

For a year, the patient reported an increase in the frequency of epileptic seizures despite the strengthening of antiepileptic treatment. The treatment was well taken and depakinemia was in the therapeutic range.

The patient was referred to our department for further explorations and adapted management.

The somatic examination was without abnormalities; especially the patient was afebrile, conscious and well oriented, and without motor or sensory deficit.

Cerebral CT scan showed the presence of multiple intracerebral calcifications with bilateral and symmetrical distribution, particularly in the central gray nuclei consistent with the diagnosis of FD (Fig.1,2, and 3).

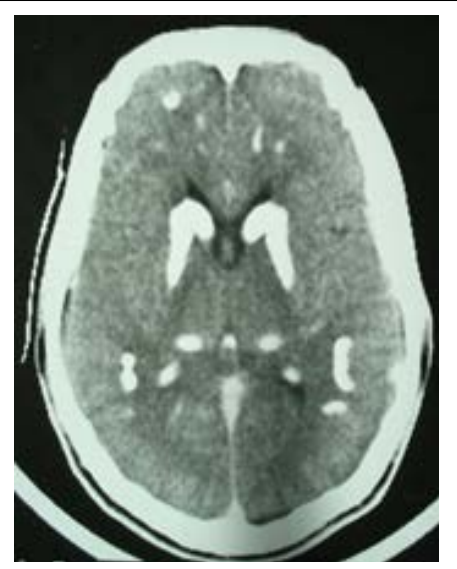

Figure 1: CT-scan in axial section, parenchymatous window: multiple bilateral and symmetrical calcifications of basal ganglia.

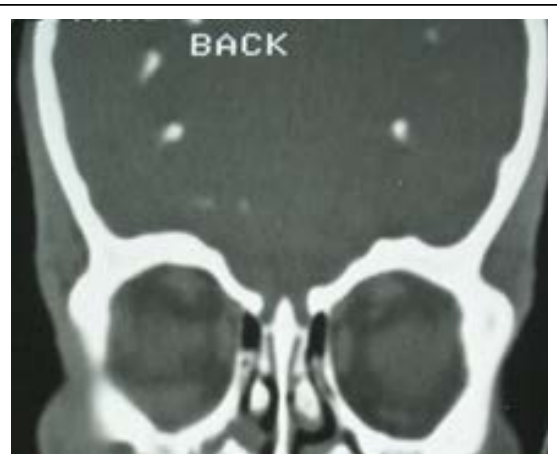

Figure 2: Brain CT in coronal reconstruction, bone window: multiple bilateral and symmetrical calcifications of basal ganglia.

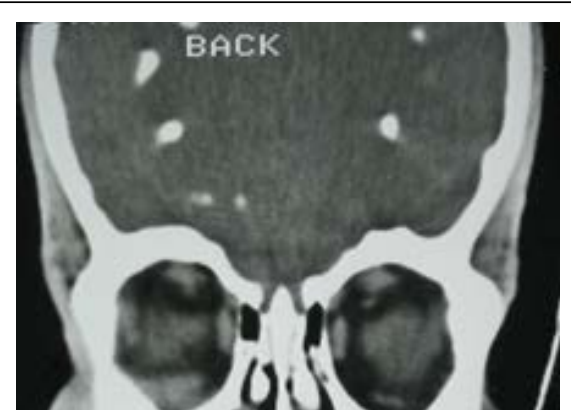

Figure 3: CT brain in coronal reconstitution, parenchymatous window: multiple calcifications bilateral and symmetrical of the central gray nuclei.

The phosphocalcic balance showed hypercalcemia at 2.70 $\mathrm{mmol} / \mathrm{l}$, hypophosphatemia at $0.4 \mathrm{mmol} / \mathrm{l}$, and the parathyroid hormone was increased to $172 \mathrm{ng} / \mathrm{l}$ confirming the diagnosis of associated primary hyperparathyroidism. Cervical ultrasound revealed an upper left parathyroid nodule.

Other basic biological tests were within normal limits: erythrocyte sedimentation rate, $\mathrm{C}$ reactive protein, hemoglobin, leucocytes, platelet, ionogram, creatinine, glomerular filtration rate, glycaemia, liver enzymes, muscle enzymes, total cholesterol, triglycerides, serum protein electrophoresis, thyroid tests, and urine analysis.

The patient was medically treated for his hypercalcemia and referred for surgical cure of his parathyroid adenoma. He was operated with simple operative follow-ups and histological examination confirmed the diagnosis of a simple parathyroid adenoma.

The subsequent evolution was marked by the normalization of the calcemia and the net regression of the frequencies and the intensity of the seizures. Doses of valproic acid were significantly reduced.

\section{Discussion}

The main neurological manifestations of FD are extrapyramidal syndrome (rigidity-hypokinesia)/parkinsonism, movements disorders, cognitive impairment, and mood changes [2,3,4,6,11]. Seizures, encephalopathy, pseudo-stroke (MELAS syndrome), early dementia, confusional syndrome, psychosis, cerebellar ataxia, schizophrenia, and mental retardation are rarely reported $[2,3,4,6,11,12,13]$. Epilepsy is an exceptional and not well-known neurological manifestation of FD $[2,10,12]$ explaining that the diagnosis of FD is most often fortuitous during a seizure episode, based on the data of the brain imaging $[5,8,14]$.

The epilepsy associated with FD can be of several types: grand mal [3,6,15]; focal epilepsy [2]; frontal lobe epilepsy [9]; complex partial seizure [10] and West syndrome [16]. Epilepsy may exceptionally be the first manifestation of FD in both sporadic $[5,6,8,10,14]$ and familial forms $[2,9]$ and at any age. Indeed, 
Citation: Bouomrani S, Guermazi M, Regaieg N, Yahyaoui S (2019) Epilepsy Revealing Fahr's Disease Associated with Hyperparathyroidism. Curr Adv Neurol Neurol Disord 2019: 52-55. DOI: https://doi.org/10.29199/2637-6997/CANN-201023

FD-associated epilepsy has been reported in pediatric patients [2], adolescents [14,17], adults $[4,8,10,15]$, and even geriatrics [6]. Lack of knowledge of this possible complication of FD is often the cause of sometimes significant diagnostic delay $[6,11,14,17]$.

Epilepsy during FD is classically recurrent, poorly responding to, or even refractory to, antiepileptic treatment $[2,4,14,17,18]$. On the other hand, the evolution is usually spectacular under adapted treatment with oral calcium and active vitamin $\mathrm{D}[4,14]$.

The pathophysiology of epilepsy during FD is variable according to the type of this disease:

1. In familial forms of FD (PFBC) epilepsy seems to be polygenic [2]. Indeed, observations by Fjaer $\mathrm{R}$ et al, of familial PFBC cases with associated epilepsy, had in addition to expressing the PFBC-specific SLC20A2 mutation, a mutation in the CHRNB2 gene responsible for the "autosomal dominant frontal lobe epilepsy" [9].

2. In sporadic or idiopathic forms of FD, seizures/epilepsy are mainly secondary to associated abnormalities of phosphocalcic metabolism, particularly hypocalcemia secondary to hypoparathyroidism $[10,11,14]$.

Indeed, it is well known that FD is classically associates with parathyroid disorders, particularly with primary hypoparathyroidism and more rarely with secondary hypoparathyroidism or pseudohypoparathyroidism $[6,11,14,15]$. The abnormalities of the phosphocalcic metabolism are a factor potentiating the own epileptogenic status of this entity.

Our observation is distinguished by the association of FD with primary hyperparathyroidism which is not classical. The convulsions thus had a twofold component: the underlying FD and recent exacerbations were related to hypercalcemia.

\section{Conclusion}

Our observation is distinguished by the association of FD with hyperparathyroidism and by the exceptional mode of revelation of this disease: epilepsy. This observation is also original in that surgical excision of the parathyroid adenoma significantly improved outcome of epilepsy, with a clear reduction in the frequency of seizures and decrease in the required doses of anticonvulsant treatment.

The FD deserves to be known and screened for when the cause of seizures or epilepsy cannot be proven, especially since it is often associated with parathyroid disorders whose timely treatment can avoid secondary sometimes serious complications.

\section{References}

1. Fahr T (1930) Idiopathische verkalkung der hirngefässe. Zentrabl Allg Pathol. 50:129-133.

2. Knowles JK, Santoro JD, Porter BE, Baumer FM (2018) Refractory focal epilepsy in a paediatric patient with primary familial brain calcification. Seizure 56: 50-52.

3. Wang H, Shao B, Wang L, Ye Q (2015) Fahr's disease in two siblings in a family: A case report. Exp Ther Med 9: 1931-1933.

4. Lee YJ, Park S, Kim YW, Park KM, et al. (2018) A Case of Seizure Revealing Fahr's Syndrome with Primary Hypoparathyroidism. Am J Case Rep19: 1430-1433.

5. Chouaib N, Rafai M, Belkouch A, Bakkali H, Belyamani L (2015) Fortuitous discovery of Fahr's syndrome after seizures. Rev Neurol (Paris) 171: 894-855.

6. Dos Santos VM, Da Mata AM, Ribeiro KR, Calvo IC (2016) Fahr's Syndrome and Secondary Hypoparathyroidism. Rom J Intern Med 54: 63-65.

7. Shafaq S, Hafiz MA, Maheen A, Anwar S, Saleem M, et al. (2013) Fahr's syndrome: Literature review of current evidence. Orphanet $J$ Rare Dis 8:156.

8. Sentimentale A, Matteoli M, Giovannelli M, De Dominicis C, Corsino M, et al. (2010) Fahr's disease detected on a head CT scan in patient with "epileptic syncope" in the Emergency Department. Intern Emerg Med 5: 263-265.

9. Fjaer R, Brodtkorb E, Øye AM, Sheng Y, Vigeland MD, et al. (2015) Generalized epilepsy in a family with basal ganglia calcifications and mutations in SLC20A2 and CHRNB2. Eur J Med Genet. 58: 624-628.

10. Hoque MA, Siddiqui MR, Arafat $Y$, Khan SU, Rahman KM, et al (2010) Fahr's disease: a very rare cause of epilepsy. Mymensingh Med J 19:127-129.

11. el Maghraoui A, Birouk N, Zaim A, Slassi I, Yahyaoui M, (1995) syndrome and dysparathyroidism. 3 cases. Presse Med 24: 1301-1304.

12. Rangaswamy, Ranjith V, Vikas L, Santosh R (2016) Fahr's Disease with Seizure Presentation. J Assoc Physicians India 64: 85-86.

13. Naqvi S, Arshad S, Hanif R, Elfert KAH (2017) Fahr's Syndrome Misdiagnosed as Schizophrenia: A Case Report. Cureus 9: e1071.

14. Hmami F, Chaouki S, Benmiloud S, Souilmi FZ, Abourazzak S, et al. (2014) Seizures revealing phosphocalcic metabolism abnormalities. Rev Neurol (Paris) 170: 440-444.

15. Morgante L, Trimarchi F, Benvenga S (2002) Fahr's disease. Lancet 359: 759

16. Origuchi $Y$ (1989) A case of Fahr's disease showing West syndrome at the onset. No To Hattatsu. 21: 499-501.

17. Mookerjee A, Mehta A, Chaddha U, Desai S (2013) Fahr's disease. BMJ Case Rep pii: bcr2013201556.

18. Arias Mayorga J, González Martín T, Escorial Miguel C, Marañón Cabello A (1991) Intracranial calcifications in the differential diagnosis of epileptic disease. Rev Clin Esp 189: 425-427. 
Citation: Bouomrani S, Guermazi M, Regaieg N, Yahyaoui S (2019) Epilepsy Revealing Fahr's Disease Associated with Hyperparathyroidism. Curr Adv Neurol Neurol Disord 2019: 52-55. DOI: https://doi.org/10.29199/2637-6997/CANN-201023

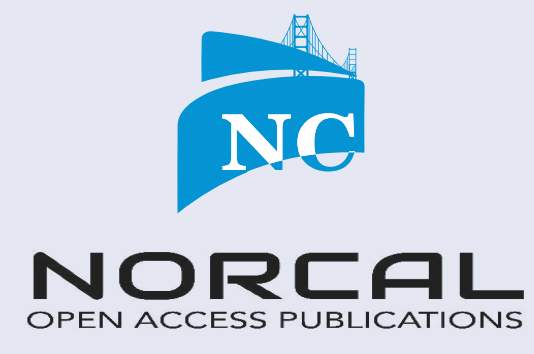

submit your manuscripts at www. norcaloa.com 